\title{
Managing Product Returns: The Role of Forecasting
}

\author{
Beril Toktay, Erwin A. van der Laan, Marisa P. de Brito
}

\begin{tabular}{|l|l|}
\hline \multicolumn{2}{|l|}{ ERIM REPORT SERIES RESEARCH IN MANAGEMENT } \\
\hline ERIM Report Series reference number & ERS-2003-023-LIS \\
\hline Publication & March 2003 \\
\hline Number of pages & 27 \\
\hline Email address corresponding author & elaan@fac.fbk.eur.nl \\
\hline Address & Erasmus Research Institute of Management (ERIM) \\
& Rotterdam School of Management / Faculteit Bedriffkunde \\
& Rotterdam School of Economics / Faculteit Economische \\
& Wetenschappen \\
& Erasmus Universiteit Rotterdam \\
& P.O. Box 1738 \\
& 3000 DR Rotterdam, The Netherlands \\
& Phone: +31 10 408 1182 \\
& Fax: $\quad+31104089640$ \\
& Email: info@erim.eur.nl \\
& Internet: $\quad$ www.erim.eur.nl \\
\hline
\end{tabular}

Bibliographic data and classifications of all the ERIM reports are also available on the ERIM website: www.erim.eur.nl 


\section{ERASMUS RESEARCH INSTITUTE OF MANAGEMENT}

REPORT SERIES

RESEARCH IN MANAGEMENT

\begin{tabular}{|c|c|c|}
\hline \multicolumn{3}{|c|}{ BIBLIOGRAPHIC DATA AND CLASSIFICATIONS } \\
\hline Abstract & \multicolumn{2}{|c|}{$\begin{array}{l}\text { In this article, we discuss ways of actively influencing product returns and we review data-driven } \\
\text { methods for forecasting return flows that exploit the fact that future returns are a function of past } \\
\text { sales. In particular we assess the value of return forecasting at an operational level, specifically } \\
\text { inventory control. We conclude with implications for supply chain management. }\end{array}$} \\
\hline \multirow{3}{*}{$\begin{array}{l}\text { Library of Congress } \\
\text { Classification } \\
\text { (LCC) }\end{array}$} & $5001-6182$ & Business \\
\hline & $5201-5982$ & Business Science \\
\hline & HD9975 & Recycling industry \\
\hline \multirow{4}{*}{$\begin{array}{l}\text { Journal of Economic } \\
\text { Literature } \\
\text { (JEL) }\end{array}$} & M & Business Administration and Business Economics \\
\hline & M 11 & Production Management \\
\hline & R 4 & Transportation Systems \\
\hline & L23 & Organization of production \\
\hline \multirow{4}{*}{$\begin{array}{l}\text { European Business Schools } \\
\text { Library Group } \\
\text { (EBSLG) }\end{array}$} & $85 \mathrm{~A}$ & Business General \\
\hline & $260 \mathrm{~K}$ & Logistics \\
\hline & $240 \mathrm{~B}$ & Information Systems Management \\
\hline & $260 M$ & Inventory and materials management \\
\hline \multicolumn{3}{|c|}{ Gemeenschappelijke Onderwerpsontsluiting (GOO) } \\
\hline \multirow[t]{4}{*}{ Classification GOO } & 85.00 & Bedrijfskunde, Organisatiekunde: algemeen \\
\hline & 85.34 & Logistiek management \\
\hline & 85.20 & Bestuurlijke informatie, informatieverzorging \\
\hline & 85.35 & Productiemanagement \\
\hline \multirow[t]{3}{*}{ Keywords GOO } & \multicolumn{2}{|c|}{ Bedrijfskunde / Bedrijfseconomie } \\
\hline & \multicolumn{2}{|c|}{ Bedrijfsprocessen, logistiek, management informatiesystemen } \\
\hline & \multicolumn{2}{|c|}{ Recycling, forecasting, bedrijfsinformatie, voorraadbeheer, ketenbeheer } \\
\hline Free keywords & \multicolumn{2}{|c|}{ Reverse Logistics, Forecasting, Information, Inventory Management, Supply chain management } \\
\hline
\end{tabular}




\title{
Managing Product Returns: The Role of Forecasting
}

\author{
Beril Toktay \\ Technology Management \\ INSEAD \\ 77305 Fontainebleau, France \\ beril.toktay@insead.edu \\ Erwin A. van der Laan \\ Rotterdam School of Management \\ Marisa P. de Brito \\ Rotterdam School of Economics \\ Erasmus University Rotterdam \\ P.O. Box 1738, 3000 DR Rotterdam, The Netherlands \\ elaan@fbk.eur.nl; debrito@few.eur.nl
}

Working Paper/Version March 2003

\begin{abstract}
In this article, we discuss ways of actively influencing product returns and we review data-driven methods for forecasting return flows that exploit the fact that future returns are a function of past sales. In particular we assess the value of return forecasting at an operational level, specifically inventory control. We conclude with implications for supply chain management.
\end{abstract}

Keywords. Reverse Logistics, Forecasting, Information, Inventory Management, Supply chain management.

\section{Introduction}

An important challenge arising in reverse logistics supply chains is the effective use of returns so as to maximize the value of this resource. To this end, decisions at strategic, tactical and operational levels should explicitly incorporate information about return flow characteristics, primarily quantity and quality. In this article, we review informational issues concerning 
product returns. We then investigate the value of accurate forecasting at an operational level by focusing on inventory control.

Most remanufacturable products are sold to the customer and are returned when their useful life is over or when the customer wants to trade in the product for an upgrade. In the former category are products such as single-use cameras, toner cartridges and tires. In the latter category are durable products such as personal computers, cars and copiers. Predicting the return flow characteristics is important for decisions at all levels, for example, for network design at the strategic level; for procurement decisions, capacity planning, collection policy and disposal management at the tactical level; and for production planning and inventory control at the operational level. We start by discussing the information needs for these decisions as modelled in the remainder of this book.

Fleischmann et al. (2003) considers network design for a reverse logistics supply chain. The return flow information required by proposed models consists of the aggregate return volume in each period over the planning horizon. These volumes must be estimated before the product is launched and before any sales information is available. They are therefore based on demand forecasts and an estimate of the proportion of sales that will be returned. A robustness analysis in Fleischmann et al. (2003) shows that the solution to the network design problem is robust in the proportion of returns, so a rough estimate based on expert judgment should be sufficient. In countries where legislation stipulates target return rates, this target can be taken as the proportion of products that will be returned.

At a tactical level, Kiesmüller et al. (2003) develop a model to determine new product production rates (and therefore the procurement and capacity needs) over the life-cycle of a remanufacturable product, taking the trajectory of demand and return volumes as input. Building warehousing capacity to handle returns, also a mid-term decision, depends on expected return volumes (De Brito and De Koster, 2003). Within a particular network design, the relationships with the parties involved can be designed in various ways so as to impact the quantity and timing of returns. We discuss this idea in more depth in Section 2. While such tactical decisions will initially be made based on expert judgement, they are typically reversible, so they can be reset iteratively - if necessary - as new information about return volumes becomes available.

At an operational level, one can assume that strategic and tactical-level decisions have been made and are fixed. The information required by models 
in Van der Laan et al. (2003) and Inderfurth et al. (2003) on inventory control and production planning, respectively, are the expectation and variance of returns in future periods. As time goes on, detailed data becomes available regarding sales volumes, return quantities and qualities. In this case, accurate data-based predictions of the quantities to be returned in each period, as well as the quality of these returns, can be made for use in inventory control and production planning. Note that some products are leased to customers (e.g. Xerox copiers to corporate customers) and are collected by the manufacturer at the expiration of the lease. In this case, the timing and the quantity of products to be returned are easier to predict. The major uncertainty is about the condition of the product.

One example of a successful remanufactured product line is the Kodak single-use flash camera (Goldstein, 1994). The reusable parts (the circuit board, plastic body and lens aperture) of the returned cameras are put back into production after inspection. The circuit board is the primary cost driver for this product. Used boards are valuable to Kodak as long as the product design allows them to be reused, and have minimal salvage value otherwise. Let us consider a number of strategic, tactical and operational issues that arise in managing this product line.

At a strategic level, the timing of new product introductions should take return flow characteristics into account. For example, the initial design of the product was constrained by the size of the circuit board. Subsequently, Kodak introduced a pocket-size camera that required a smaller circuit board. As a result, a number of larger-size boards would become obsolete by the time they were returned to Kodak. In this setting, forecasting the quantity and timing of returns of the previous generation is an important input in determining the timing of the new product introduction.

At a tactical level, consider the after-use returns. Customers take the used cameras to a photofinishing laboratory, where the film is taken out and processed; only the film and the developed pictures are returned to the customer. Kodak needs to propose a collection policy to the laboratories that is economical and yet encourages them to return the cameras to Kodak. This policy should also take into account differences between laboratories: Due to economies of scale in transportation, small labs may wait for a long time before sending a batch back to Kodak or may not send in cameras at all, significantly adding to the return delay and influencing the return percentage, which in turn impacts the profit of the product line.

Again at the tactical level, consider the procurement of new circuit boards. 
An important decision is whether to source locally or overseas (at a lower cost, but incurring a longer lead time). The proportion of returns will determine the volume of new circuit boards that is required, so estimating this number is important in making the sourcing decision.

Finally, at an operational level, consider the inventory management of new circuit boards. The production facility uses both old and new components to manufacture new cameras. Since circuit boards are costly, recuperating these components from used products is a valuable opportunity. Forecasting returns to a good degree of accuracy and incorporating these forecasts in inventory management decisions improves the value extracted from this resource.

Unlike end-of-life returns that have already been sold for profit and now have the potential of generating additional benefits through value recovery, commercial returns represent a lost margin. In catalog sales, an average return rate of $12 \%$ is standard, with return rates varying by product category: $5-9 \%$ in hard goods, $12-18 \%$ for casual apparel, $15-20 \%$ for hightech products, and up to 35\% for high fashion apparel (Dowling, 1999). Commercial returns impose high costs on retailers and manufacturers alike. For example, at HP Inkjet Imaging Solutions, product returns have been averaging $6.6 \%$ of sales dollars and $5.7 \%$ of units shipped in North America in 1999 (Guide and Van Wassenhove, 2002). Like end-of-life returns, an important lever in managing commercial returns is to accurately predict the return quantities for both tactical and operational level decisions.

There are few documented business examples of forecasting specifically for reverse logistics. What has been documented is basic: estimating the return probability by the proportion of cumulative returns to cumulative sales (Goh and Varaprasad, 1986; Toktay et al., 2000). We refer to this method as "naive estimation." It is useful only for tactical decisions such as capacity sizing since it only provides information on the overall proportion of returns but not on their timing. At a more operational level, supply chain planning and inventory software applications that allow for remanufacturing typically do so by providing the capability to do reverse-logistics-specific order processing; to the best of our knowledge, the forecasting of returns, if any, is handled by applying time series forecasting methods to the historical return stream without exploiting the fact that returns are generated by previous sales (e.g. Genco, ReturnCentral, Xelus).

In this article, we discuss ways of actively influencing returns (Section 2) and we review data-driven methods for forecasting return flows that exploit 
the fact that future returns are a function of past sales. In particular, Section 3 builds the two stages of forecast model building/parameter estimation and return forecasting. We then focus on the value of return forecasting at an operational level, specifically inventory control. Section 4 uses simulation to evaluate the performance of a periodic-review replenishment policy along two dimensions: the impact of estimation error and order variability. We conclude in Section 5 with implications for supply chain management.

\section{Influencing Returns}

An important consideration in extracting value from returns is to actively manage their quantity and timing. Indeed, retailers and manufacturers strive to design reverse logistics systems that increase the visibility and speed of the return process to maximize asset recovery, especially for seasonal or short lifecycle products. Firms vary in how they address this problem. For example, Ingram Micro Logistics, the distribution arm of Ingram Micro, opened the first automated returns facility in the US in early 2001 (Morrell, 2001). Others increasingly rely on third-party reverse logistics providers such as GENCO Distribution System, UPS, USF Processors, Returns Online (Kokkinaki et al. (2003); Gooley, 2001). Various software products that are specifically targeted towards returns processing are now available on the market, provided by such companies as Kirus Inc., Retek.com, ReturnCentral and The Return Exchange (Gooley, 2001).

This issue has recently started to be addressed in the reverse logistics literature. Hess and Mayhew (1997) develop a regression model for commercial returns that incorporates explanatory variables such as price, product category and reason for return. This model is then used to predict the cumulative return rate over time. In this case, the analysis is very valuable for identifying the most important reasons for return, for forecasting the profitability of product categories using projected returns, and as input into replenishment orders. Savaşkan et al. (1999) show that decisions about who is responsible for the collection of returns can influence return volumes. Guide and Van Wassenhove (2000) and Klausner and Hendrickson (2000) show that offering differentiated take-back prices to consumers based on the product model and product quality can influence the quality and quantity of returns.

Two different modelling approaches are useful in capturing the dependence of return flow characteristics on system structure and parameters. The 
first approach is to develop principle-agent models and explore the value of incentive schemes such as return allowances, trade-in offers and buybacks (as reviewed in more generality in Debo et al. (2003). The second is data-based regression analysis to quantify the impact of several relevant factors in specific settings. We believe that for practical implementation, the data-based approach holds much potential. Developing a good understanding of drivers of return flow characteristics (e.g. product category, life-cycle length, market value of used product, customer segment, ease of return, rebate policy, etc.) would enable better decision making for the following purposes:

- Influencing return delay. Especially for items that depreciate rapidly, getting the used products back quickly for reprocessing is very valuable. A statistical investigation of which factors are the most relevant can help in determining the most cost-effective levers in reducing the return delay.

- Developing customer- or category-specific return policy. Return policies typically do not distinguish between customer segments or product categories although it is clear that segmentation could result in more effective policies. In the absence of data allowing an evaluation of differentiated service contracts, it is not possible to develop such a policy in an effective manner. This gap can be filled by developing regression models that use product category and customer segment as explanatory variables.

- Trading off customer service level and cost. Typically, it is the marketing department that "develops" the return policy. The focus is on increasing customer service, especially in North America. In addition, competitive pressures drive firms towards offering liberal return policies. However, liberal return policies can be very costly due to direct costs such as transportation, testing, and repackaging, due to opportunity cost and due to legislation that sometime requires returned products to be labeled as 'used'. In determining return policies, the first step should be to evaluate the cost of alternative return policies. To this end, a model of how return rates will be impacted by the return policy needs to be developed. 


\begin{tabular}{l|l}
$s(\tau)$ & Sales in period $\tau$ \\
$u(\tau)$ & Returns in period $\tau$ \\
$p$ & Probability that a sold product will eventually return \\
$r_{k}$ & $\begin{array}{l}\text { Probability that a sold product returns after } k \text { periods, given that it will } \\
\text { return eventually }\end{array}$ \\
$\nu_{k}$ & $\begin{array}{l}\text { Probability that a sold product returns after } k \text { periods }\left(\nu_{k}=p \cdot r_{k}\right) \\
\text { The period } \tau \text { forecast of } \nu_{k}\end{array}$ \\
$\hat{\nu}_{k}(\tau)$ & The total returns in period $\tau+j$ originating from sales in period $\tau-i$ \\
$y_{\tau-i, \tau+j}$ & $\begin{array}{l}\text { Total returns up to and including period } \tau \text { originating from sales in period } \\
v_{\tau, \tau-i}\end{array}$ \\
$\mathcal{I}(\tau)$ & $\begin{array}{l}\text { Information set available at the end of period } \tau \text { to forecast future returns } \\
\text { Table 1: Main notation of Section } 3 .\end{array}$
\end{tabular}

\section{Forecasting Returns}

We now turn to the issue of forecasting returns under the assumption that all policies concerning returns have been determined and data collection on returns has started. The first step in any forecasting exercise is to build a forecast model that models the variables to be predicted as a function of the explanatory variables (Box and Jenkins, 1976). For example, the variable to be predicted may be the return quantity in the next period and the explanatory variables can be past sales. This forecast model will have a number of parameters that need to be estimated using historical sales and returns data. Once the validation and estimation phase is complete, we have a fully specified forecast model. As the second step, forecasts of future returns are made using parameter estimates obtained from this forecast model and historical information. The two subsections to follow describe methods for these two steps, respectively. Table 1 lists the main notation that is used in this section.

\subsection{Forecast Models and Parameter Estimation}

The key to forecasting returns is to observe that returns in any one period are generated by sales in the preceding periods. A prevalent way of modelling this is to assume that a sale in the current period will generate a return $k$ periods from now with probability $\nu_{k}, k=1,2, \ldots$ or will never be returned. We first review methods used in the literature that exploit this structure to postulate 
a return delay distribution and estimate its parameters; alternative modelling approaches are discussed at the end of Section 3. A particular characteristic of the return delay data is that it is right-censored: At a given time, if an item has not been returned, it is not known whether it will be returned or not. For accurate estimation, it is important to use an estimation method that takes into account that some items that have not yet been returned will never be returned.

We classify the forecast models used in the literature according to the data that they exploit. We say that period-level information is available if only the total sales and return volume in each period are known. For beverage containers, single-use cameras and toner cartridges, this is typically the only data available. We say that item-level information is available if the sale and return dates of each product are known. Electrical motors with electronic data logging technology (Klausner et al., 1998), copiers, and personal computers are typically tracked individually, so this data can easily be obtained for these products. POS (point-of-sale) data technology in retailing also can allow for item-level tracking.

\subsubsection{Period-level Information}

Let $s(\tau)$ and $u(\tau)$ denote the sales and returns of products in period $\tau$, respectively. Goh and Varaprasad (1986) propose a transfer function model of the form

$$
u(\tau)=\frac{\omega_{0}-\omega_{1} B-\omega_{2} B^{2}-\ldots-\omega_{s} B^{s}}{1-\delta_{1} B-\delta_{2} B^{2}-\ldots-\delta_{r} B^{r}} s(\tau-b)+\epsilon(\tau),
$$

where $B$ is the backshift operator, $b$ is the time lag, $\left\{\omega_{i}\right\}$ and $\left\{\delta_{i}\right\}$ are lag parameters, and $\epsilon(\tau)$ is white noise. The determination of the appropriate transfer function model follows the steps of model identification, parameter estimation and diagnostic checking as described in Box and Jenkins (1976). In this spirit, De Brito and Dekker (2001) use data on commercial returns with individual tracking to test the assumption of exponential delay.

Note that the transfer function model can be rewritten as

$$
u(\tau)=\left(\nu_{0}+\nu_{1} B+\nu_{2} B^{2}+\ldots\right) s(\tau)+\epsilon(\tau)
$$

Once the parameters $\left\{\omega_{i}\right\}$ and $\left\{\delta_{i}\right\}$ of the transfer function model have been estimated, the parameters $\left\{\nu_{k}, k \geq 0\right\}$ are easily calculated. The statistically 
significant values of these parameters are used as estimates of the probability of return after $k$ periods, for $k \geq 0$. The probability $p$ that a product is eventually returned is given by $\sum_{k=0}^{\infty} \nu_{k}$. Goh and Varaprasad use this method to estimate the return quantities of Coca-Cola bottles.

In practice, the data is augmented in each period as new sales and return information becomes available. The incremental nature of the information received makes Bayesian estimation a natural choice. Toktay et al. (2000) assume that the return process can be modeled by Equation 2 where $\nu_{k}$ has the structure $p \cdot r_{k}$; here $p$ denotes the probability that a product will ever be returned and $r_{k}$ denotes the probability that the product will be returned after $k$ periods, conditional on ever being returned. In other words, if a product was sold in period $\tau$, the probability that it comes back in period $\tau+k$ is modelled as $p \cdot r_{k}$.

The type of relation in Equation 2 is referred to as a 'distributed lag model' in Bayesian inference (Zellner, 1987). Usually, a specific form of distribution involving one or two parameters is assumed for the lag, which reduces the number of parameters to be estimated. The estimation procedure for a geometrically distributed lag with parameter $q$ (the probability that a sold product is returned in the next period, given that it will be returned; $\left.r_{k}=q(1-q)^{k-1}\right)$ is illustrated in Toktay et al. (2000). They apply this method to data obtained from Kodak on sales and returns of single-use flash cameras.

\subsubsection{Item-Level Information}

When items are tracked on an individual basis, it is possible to observe the actual return delay of returned items. In a given period $\tau$, define $v_{\tau, \tau-i}$ as the number of items sold in period $\tau-i$ that have been returned up to and including period $\tau$, where $i>0$. For these items, the return delay is known exactly. For items that have not been returned yet, it is known that the delay is longer than the elapsed time, or possibly infinite (corresponding to a product never being returned). A simple sample average of this sample data would give biased estimates due to the right-censoring of the data. Dempster et al. (1977) introduce the Expectation Maximization (EM) algorithm to compute maximum likelihood estimates given incomplete samples. This algorithm can be effectively used to estimate the return delay distribution using censored delay data. The EM algorithm is illustrated in Toktay et al. (2000) for geometric and Pascal delay distributions. 


\section{2 $\quad$ Forecasting Returns}

Given past sales volumes and estimates of the return probability and the return delay distribution, it is possible to forecast future returns based on a number of different information sets. Denote by $\mathcal{I}(\tau)$ the information available at the end of period $\tau$ that will be used for forecasting future returns, and by $\hat{\nu}(\tau)$ the period- $\tau$ estimate of the vector $\nu$. In particular, Kelle and Silver (1989a) define

- $\mathcal{I}_{A}(\tau)=\{\hat{\nu}\}$ (estimate of $\left.\nu\right)$,

- $\mathcal{I}_{B}(\tau)=\{\hat{\nu}(\tau),\{s(\tau-i), i=0,1, \ldots, \tau\}\}$ (estimate of $\nu$ and historical period-level sale information),

- $\mathcal{I}_{C}(\tau)=\{\hat{\nu}(\tau),\{s(\tau-i), u(\tau-i), i=0,1, \ldots, \tau\}\}$ (estimate of $\nu$ and historical period-level sale and return information), and

- $\mathcal{I}_{D}(\tau)=\left\{\hat{\nu}(\tau),\left\{s(\tau-i), v_{\tau, \tau-i}, i=0,1, \ldots \tau\right\}\right\}$ (estimate of $\nu$ and historical item-level sale and return information).

Define the random variable $y_{\tau-i, \tau+j}$ as the number of returns in period $\tau+j$ originating from sales in period $\tau-i$. Under the assumption that all period demands are mutually independent and returns from different demand issues are not correlated, Table 2 lists the expressions for $\mathrm{E}\left[y_{\tau-i, \tau+j} \mid \mathcal{I}(\tau)\right]$ based on one of the information sets $\mathcal{I}_{A}(\tau), \mathcal{I}_{B}(\tau), \mathcal{I}_{C}(\tau)$, or $\mathcal{I}_{D}(\tau)$. The first two columns of the table forecast future returns based on past and current sales. The third column forecasts future returns based on future sales (and uses the period- $\tau$ estimate of $\nu$ ). In this table, $\hat{c}(i, j)$ is a factor that takes into account the correlation between the observed returns to date and the future returns. An exact expression for $\hat{c}(i, j)$ is not available in general, but Kelle and Silver develop an approximation. The variance of future returns can also be calculated, although these expressions are slightly more complicated (see Kelle and Silver, 1989a). The total number of returns in period $\tau+j$ is simply given as $u_{\tau+j}=\sum_{i=-(j-1)}^{\tau} y_{\tau-i, \tau+j}$, the mean and variance of which can be calculated from those of its mutually independent elements. The table clearly shows that the expressions for the expected future returns $\mathrm{E}\left[y_{\tau-i, \tau+j} \mid \mathcal{I}(\tau)\right]$ only differ in returns from sales in past periods, i.e. $i=0,1, \ldots, \tau$.

There are two recent papers that go beyond using past sales and returns data to forecast future returns. As mentioned in Section 2, Hess and Mayhew (1997) develop a regression model for commercial returns that incorporates 


\begin{tabular}{|c|c|c|c|}
\hline \multirow{2}{*}{$\begin{array}{l}\text { Information } \\
\text { set }\end{array}$} & \multicolumn{3}{|c|}{$\mathrm{E}\left[y_{\tau-i, \tau+j} \mid \mathcal{I}(\tau)\right]$} \\
\hline & $i>0$ & $i=0$ & $i<0$ \\
\hline $\mathcal{I}_{A}(\tau)$ & \multicolumn{3}{|c|}{ not applicable } \\
\hline $\mathcal{I}_{B}(\tau)$ & \multicolumn{2}{|l|}{$\hat{\nu}_{j+i}(\tau) s(\tau-i)$} & $\hat{\nu}_{j+i}(\tau) \mathrm{E}(s(\tau-i))$ \\
\hline $\mathcal{I}_{C}(\tau)$ & $\hat{\nu}_{j+i}(\tau) s(\tau-i)+\hat{c}(i, j)$ & $\hat{\nu}_{j}(\tau) s(\tau)$ & $\hat{\nu}_{j+i}(\tau) \mathrm{E}(s(\tau-i))$ \\
\hline $\mathcal{I}_{D}(\tau)$ & $\frac{\hat{\nu}_{j+i}(\tau)}{1-\sum_{k=1}^{i} \hat{\nu}_{k}(\tau)}\left(s(\tau-i)-v_{\tau, \tau-i}\right)$ & $\hat{\nu}_{j}(\tau) s(\tau)$ & $\hat{\nu}_{j+i}(\tau) \mathrm{E}(s(\tau-i))$ \\
\hline
\end{tabular}

Table 2: The expectation of $y_{\tau-i, \tau+j}$, the number of returns in period $\tau+j$ from sales in period $\tau-i$, for various information sets.

explanatory variables in predicting the cumulative return rate over time. Marx-Gómez et al. (2002) develop a fuzzy inference system for the forecasting of returns. This approach develops a rule-base using expert knowledge and then refines the rule-base through training on data.

\section{Performance Measurement}

The previous section introduced some forecast models and related return forecasting methods. In this section, we compare the performance of these forecasting methods in a specific context - that of inventory management.

Although there are many papers on inventory management using returned products (Van der Laan et al. (2003)), very few consider the joint forecasting and inventory management of returned products (Kelle and Silver, 1989a,b; Kiesmüller and van der Laan, 2001; Toktay et al., 2000).

Under fixed ordering costs, Kelle and Silver (1989b) formulate a deterministic dynamic lot sizing problem taking into account future returns in net demand forecasts. These forecasts are generated by using methods developed 
in Kelle and Silver (1989a). The impact of future returns is that net demand may be negative. The authors develop a transformation into the nonnegative demand case. The Wagner-Whitin deterministic lot-sizing procedure can then be applied to determine procurement quantities in each period.

Kiesmüller and van der Laan (2001) do not focus on forecasting as such, but explicitly model the dependence between the demand and return process by a fixed lag. They conclude that neglecting the dependency structure leads to reduced system performance. Using a simple forecast of expected future returns, depending on the number of items sold in the past and the return probability, considerably improves performance.

Toktay et al. (2000) model a reverse logistics supply chain using a closed queueing network. They develop and implement adaptive estimation and control methods to dynamically determine the procurement quantities of new components. This is the only paper to compare the impact of using different dynamic forecast update mechanisms on supply chain performance.

This section expands on the performance analysis of reverse logistics supply chains. In particular, $\S 4.1$ investigates the robustness of the system cost to parameter estimation error in an inventory management setting. The first part of this discussion is based on De Brito and Van der Laan (2002) who investigate the impact of using static but erroneous parameter estimates. The second part extends the discussion to the impact of using dynamically updated parameter estimates. The analysis in $\S 4.1$ is for a single stage. At a supply chain level, the order variability induced in each stage is known to impact the overall performance of the system. This angle has not been studied in a reverse logistics setting. §?? we analyzes the performance of the forecasting methods of Section 3 with respect to order variability. The additional notation used in this section is listed in Table 3.

\subsection{Robustness of Expected Cost to Parameter Esti- mation Error}

We consider a single-product periodic-review inventory system with no fixed ordering cost and linear holding and backorder costs. Each individual demand returns according to a distribution $\nu$. The replenishment lead time is a fixed constant $L$. Demands that cannot be satisfied immediately are fully backordered. In this setting, a simple base-stock policy is optimal when the expectation and variance of the net lead time demand, $N D_{L}(\tau) \doteq$ 


\begin{tabular}{l|l}
$N D(\tau)$ & Net demand (demand minus returns) in period $\tau$ \\
$L$ & Replenishment lead time \\
$N D_{L}(\tau)$ & Net demand during lead time (periods $\tau+1, \tau+2, \ldots \tau+L$ ) \\
$S(\tau)$ & Base stock level at the end of period $\tau$ \\
$O(\tau)$ & Order quantity at the end of period $\tau$ \\
$k$ & Safety factor \\
$h_{s}$ & Holding cost per product per period \\
$c_{b}$ & Stockout penalty per occurrence \\
$\mu_{D}$ & Mean of demand per period \\
$\sigma_{D}$ & Standard deviation of demand per period \\
$\sigma_{O(\tau)}$ & Standard deviation of the order quantity in period $\tau$ \\
$\sigma_{N D(\tau)}$ & Standard deviation of the net demand in period $\tau$
\end{tabular}

Table 3: Additional notation of Section 4

$D_{L}(\tau)-R_{L}(\tau)$, are known for each period $\tau$ (Kelle and Silver, 1989a). If $N D_{L}(\tau)$ has a normal distribution, the base-stock level is defined as $S=\mathrm{E}\left[N D_{L}(\tau)\right]+k \cdot \sqrt{\operatorname{Var}\left[N D_{L}(\tau)\right]}$, where $\mathrm{E}\left[N D_{L}(\tau)\right]$ and $\operatorname{Var}\left[N D_{L}(\tau)\right]$ are the expectation and variance of the net demand during the replenishment lead time, respectively (Silver and Petersen, 1985, Ch. 7). The safety factor $k$ is determined according to the desired performance level.

Kelle and Silver (1989a) develop normal approximations for $N D_{L}(\tau) \mid \mathcal{I}(\tau)$, the conditional net demand over the replenishment lead time $L$ (periods $\tau+1, \tau+2, \ldots, \tau+L)$, given information up to and including period $\tau$. Kelle and Silver propose using information sets $\mathcal{I}_{A}(\tau), \mathcal{I}_{B}(\tau), \mathcal{I}_{C}(\tau)$ and $\mathcal{I}_{D}(\tau)$ defined in Section 3. We refer the reader to Kelle and Silver for the mathematical expressions for $\mathrm{E}\left[N D_{L}(\tau) \mid \mathcal{I}(\tau)\right]$ and $\operatorname{Var}\left[N D_{L}(\tau) \mid \mathcal{I}(\tau)\right]$ under the four information sets. Denote by $S(\tau)$ the base-stock level in period $\tau$. Then

$$
S(\tau)=\mathrm{E}\left[N D_{L}(\tau) \mid \mathcal{I}(\tau)\right]+k \sqrt{\operatorname{Var}\left[N D_{L}(\tau) \mid \mathcal{I}(\tau)\right]}
$$

and the order quantity in period $\tau, O(\tau)$, is given by

$$
O(\tau)= \begin{cases}S(\tau)-S(\tau-1)+N D(\tau) & \text { if } S(\tau-1)-N D(\tau)<S(\tau) \\ 0 & \text { otherwise }\end{cases}
$$




\subsubsection{Static Parameter Estimates}

De Brito and Van der Laan (2002) use simulation to compare the cost performance of the ordering policy given by Equation 4 under information sets A-D when parameter estimates are static and erroneous, that is, $\hat{\nu}(\tau)=\hat{\nu} \neq \nu$.

The simulation experiments are conducted in the following manner. In period $\tau$, the cumulative demand $D(\tau)$ is drawn from a normal distribution with mean $\mu_{D}$ and standard deviation $\sigma_{D}$ (values are rounded to integers; negative numbers are treated as zero). For each individual item of this cumulative demand, the probability of return of the item is drawn from a bernoulli distribution with parameter $p$; for those items that will be returned, the time to return is drawn from a geometric distribution with parameter $q$ (expected return time $1 / q)$. In this case, estimating the vector $\nu$ reduces to estimating

the parameters $p$ and $q$ since $\nu_{k}=p \cdot(1-q)^{k-1} q$. In each period, estimates of the expectation and variance of the net demand during the replenishment lead time are computed using these parameters in each of methods A-D. These estimates are subsequently used to compute the order size using Equations 3 and 4. Assuming that the net demand during lead time is normally distributed, the cost optimal value of the safety factor, $k^{*}$, satisfies (Silver and Peterson, 1985, Ch. 7)

$$
G\left(k^{*}\right)=1-\frac{h_{s}}{c_{b}},
$$

where $G($.$) is the standard normal distribution, h_{s}$ is the holding cost per item in overstock at the end of each period, and $c_{b}$ is the stockout penalty per occurrence. At the end of each simulation experiment, the total average cost per period is calculated as the total average holding plus stockout costs per period. More details regarding the simulation setup can be found in De Brito and Van der Laan (2002).

In order to investigate the effect of inaccurate parameter information, two types of errors are considered in the parameter estimates. The first is the inaccurate estimation of the overall return probability, $p$, while the shape of the return distribution is preserved. In other words, estimates $\hat{p}(\tau)=\hat{p} \neq p$ are used in each period in calculating $S(\tau)$. The second is the inaccurate estimation of the expected time-to-return, $1 / q$ : Estimates $\hat{q}(\tau)=\hat{q} \neq q$ are used in calculating $S(\tau)$. This affects the estimated shape of the timeto-return distribution, but the estimated overall return probability is kept equal to the real return probability. 
Inaccurate estimation of the return probability.

In De Brito and Van der Laan (2002), it is shown that under perfect estimation $(\hat{p}=p, \hat{q}=q)$, method $\mathrm{D}$ is superior to the other methods. This is expected since this method uses all available information correctly. The differences with respect to methods $\mathrm{B}$ and $\mathrm{C}$ are rather small unless the return probability is very high. The performance of Method A on the other hand is reported to be very poor. Its naive forecasting procedure gives a rather inaccurate forecast for the mean and variance of the lead time net demand, especially for high return rates and large lead times. As a consequence, relation (5) provides a safety factor that is far from optimal. Due to its poor performance we will not consider this method in the remainder of this section.

In case of inaccurate estimation, the authors show (see Figure 1 for an example) that an estimation error of $10 \%\left(\frac{|\hat{p}-p|}{p}=0.1\right)$ may lead to a cost increase of 10-30\% for Methods B-D. A $20 \%$ estimation error may even lead to a cost increase of more than $200 \%$ relative to the perfect information case. Clearly, overestimation of the return probability is far worse than underestimation, since overestimation leads to costly stockouts.

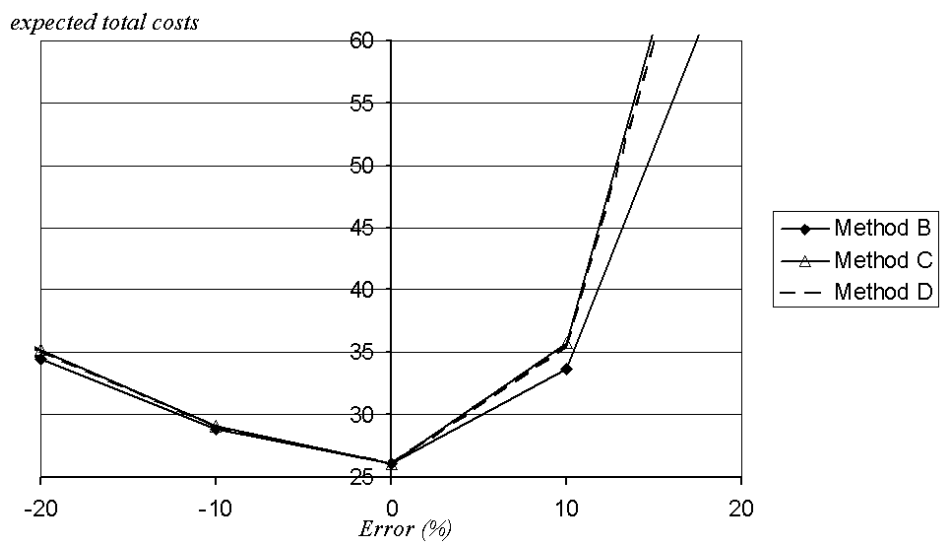

Figure 1: Impact of estimation error $(-20 \%,+20 \%)$ about the return probability $\left(\mu_{D}=30, \sigma_{D}=6, L=4, p=0.5, q=0.6, h_{s}=1, c_{b}=50\right)$.

The study furthermore shows that Method B structurally outperforms the other two methods in case of an estimation error of $10 \%$ or more, whereas Method C always performs worse. The differences between the methods 
become bigger as the return probability goes up or the lead time goes down. Inaccurate estimation of the expected time-to-return.

According to De Brito and Van der Laan (2002), the inaccurate estimation of the expected time-to-return has little effect if return rates are small. However, as can be observed in Figure 2, for $p=0.8$, Methods B and C may be far more robust with respect to estimation error than the benchmark, Method D. Also here, the differences in performance with respect to the benchmark are reported to increase with the return probability and decrease with the lead time.

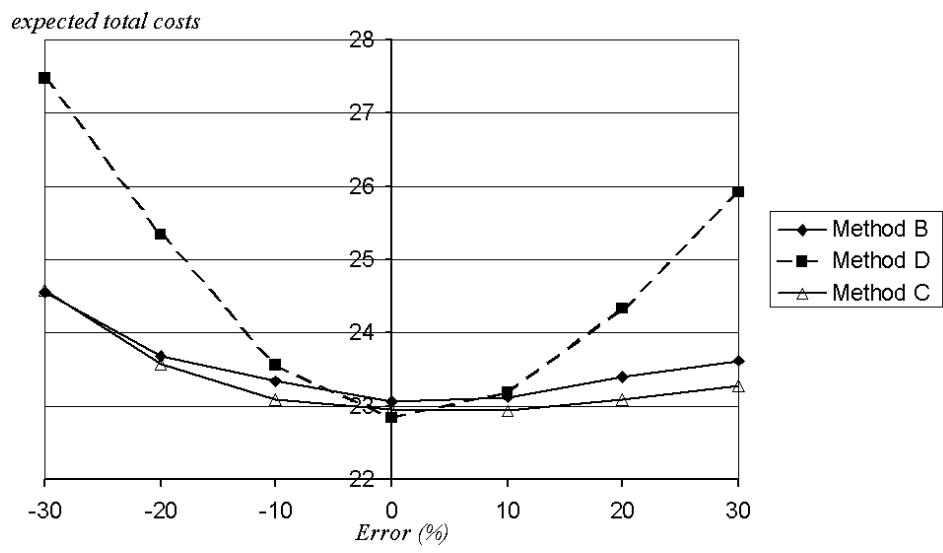

Figure 2: Impact of estimation error $(-30 \%,+30 \%)$ about the expected timeto-return $\left(\mu_{D}=30, \sigma_{D}=6, L=4, p=0.8, q=0.6, h_{s}=1, c_{b}=50\right)$

\section{Managerial Implications.}

Since the performance of Method A is very poor in general, this method is not recommended for practical implementation. Method B appears to have a sufficient level of sophistication under perfect information. The cost differences with respect to Methods $\mathrm{C}$ and $\mathrm{D}$ seem to be too small to justify large investments in data recording and analysis. Furthermore, Method B seems to be much more robust under inaccurate estimation. Method B systematically outperforms Methods $\mathrm{C}$ and $\mathrm{D}$ if the return probability estimation error is $10 \%$ or more. The cost differences are considerable if the return probability is overestimated. In general it is better to underestimate the return probability than to overestimate it, since stockouts are usually much more costly than overstocks. 


\subsubsection{Dynamically Updated Parameter Estimates}

De Brito and Van der Laan (2002) assume that parameter estimates are erroneous but static. In practice, it may be that return flow parameters are updated over time. In this case, the estimation error would be initially high, but the estimates would eventually converge to the true parameter values. In addition, the speed of convergence of parameter estimates would depend on the nature and volume of the information collected. Consequently, in choosing a particular method, one needs to strike a balance between information requirements and the need for accuracy of the inventory method in question. This section addresses this trade-off.

Methods B, C, and D all require an estimate of the return distribution. To generate these estimates, information on past sales and returns per period is required. Therefore, one can eliminate the naive estimation introduced in Section 1 from consideration, since it only generates an estimate of the return probability. On the other hand, the distributed lag bayesian inference model and the EM algorithm both generate the estimates required by these methods, with the former necessitating only period-level information (as do forecasting Methods B and C), and the latter necessitating item-level information (as does forecasting Method D). Toktay (2002) compares the convergence rates in these two models across different demand volumes, as reproduced in Figures 3 and 4.

With period-level data, the convergence of the estimate depends primarily on the number of periods of data available: In Figure 3, the estimate of the return probability converges after eighteen periods of returns for all sales volumes. The demand volume does not impact the point at which the estimate converges, but it is significant in determining the accuracy of the method in the periods up to that point.

Figure 4 shows that the speed of convergence of the EM algorithm does depend on the sales volume per period: In this example, two periods, five periods, and twenty periods, respectively, are needed for the confidence interval of the return probability estimate to include the true value of the parameter in the cases of high volume, medium volume and low volume, respectively. While it is to be expected that the accuracy of the estimate in the EM algorithm directly depends on the volume of data, it is particularly striking that the algorithm achieves such accuracy after only two periods in the high-volume scenario.

Managerial Implications. 


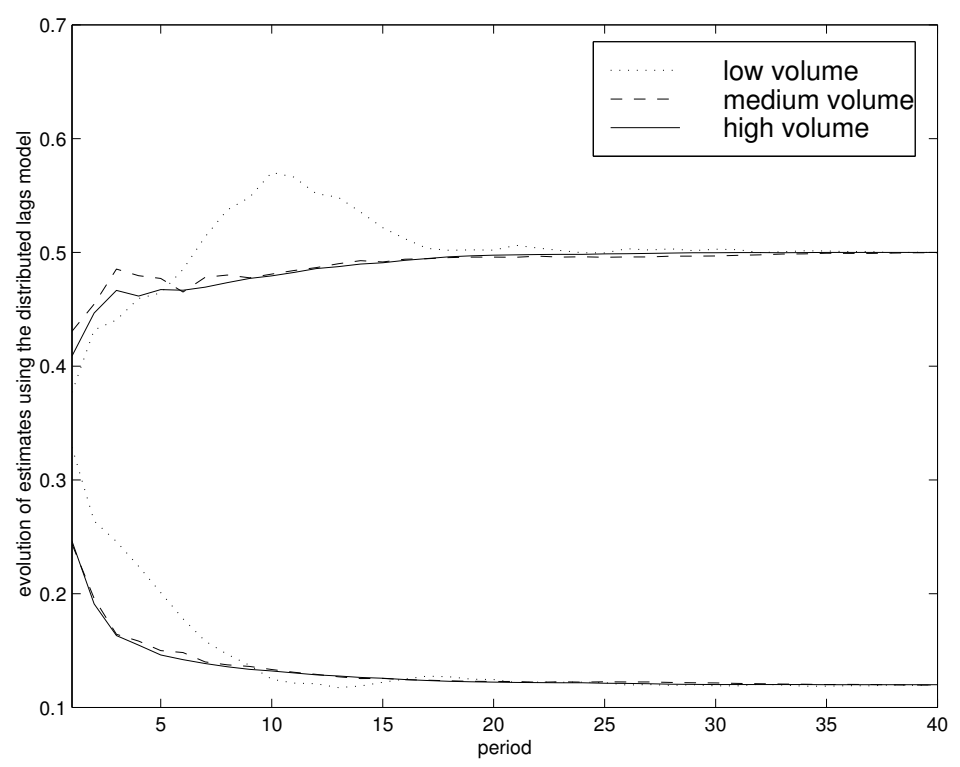

Figure 3: The top (bottom) three lines plot the evolution of the estimate of the return probability (delay) using the distributed lags model. The true values of the return probability and return delay are 0.5 and 0.125 , respectively. The number of sales in each period is a Poisson random variable with parameter 200, 2000, and 20000, respectively, labelled as low, medium and high sales volumes, respectively.

As expected, the EM algorithm clearly outperforms Bayesian inference with a distributed lags model. This is because item-level information is present in the former. However, note that for medium and high demand volumes, the latter method underestimates the return probability, while the former overestimates it. Combining this observation with results of De Brito and Van der Laan (2002) that state that overestimation is much more costly than underestimation, we conclude that using the latter method which requires only period-level information may in fact be appropriate for higher demand volume products. For low-demand items, investing in collecting item-level information does appear to be beneficial since the EM algorithm is more robust, where a method is said to be more robust if the maximum deviation from the true parameter value over time is lower. 


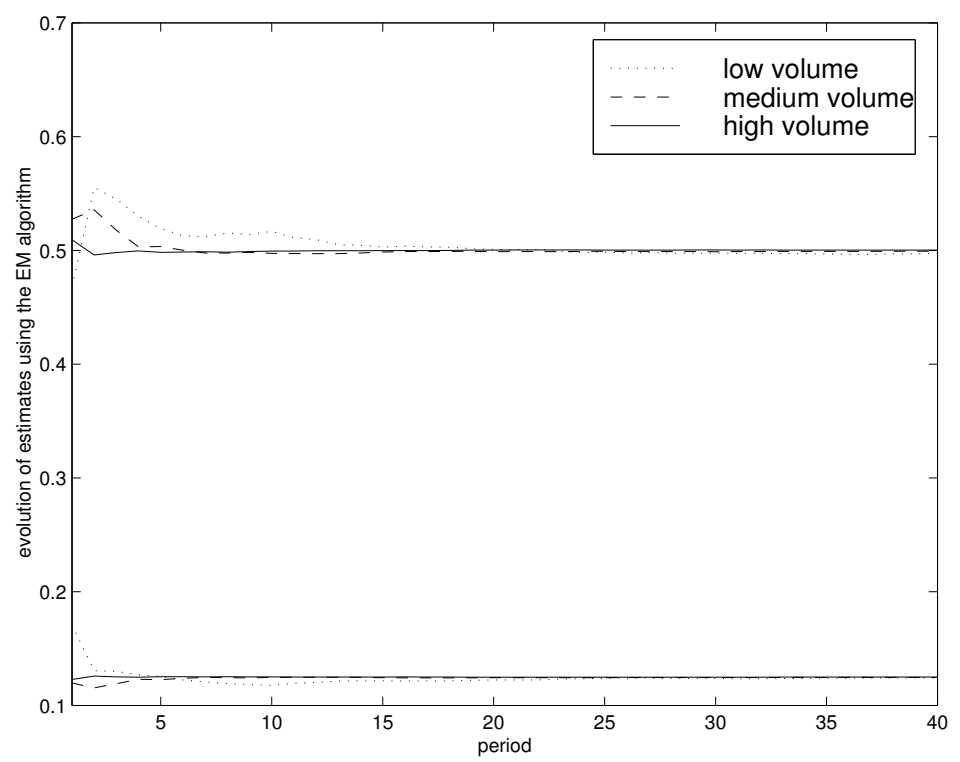

Figure 4: The top (bottom) three lines plot the evolution of the estimate of the return probability (delay) using the Expectation Maximization algorithm. The true values of the return probability and return delay are 0.5 and 0.125 , respectively. The number of sales in each period is a Poisson random variable with parameter 200, 2000, and 20000, respectively, labelled as low, medium and high sales volumes, respectively.

\subsection{Propagation of Order Variability in Reverse Logis- tics Supply Chains}

Section 4.1 considered the impact of erroneous parameter estimates on inventory costs in a single-stage model and discussed the robustness of proposed return forecasting methods to parameter estimation errors. This analysis does not focus on the impact of ordering decisions given by Equation 4 on the upstream stages.

One way of measuring the impact of local decisions on upstream stages is to measure the variance of orders placed to the upstream stage. It is wellknown that order variability at any stage of a forward supply chain tends to be larger than the demand variability; this phenomenon is called the "bullwhip effect." In the literature, several reasons have been suggested to explain the existence of the bullwhip effect in forward supply chains (Lee et al., 1997). 
In particular, when demand is correlated over time and the base-stock level is dynamically updated, the bullwhip phenomenon is observed. If demand is iid (independently and identically distributed), but its parameters are dynamically updated based on historical data, the bullwhip effect is again observed. However, when demand is iid with known parameters in a forward supply chain, no bullwhip effect is observed. To see this, note that in a forward supply chain, $N D_{L}(\tau)=D_{L}(\tau)$ since there are no returns. Therefore, the base-stock level is given by $\mathrm{E}\left[D_{L}(\tau)\right]+k \operatorname{Var}\left[D_{L}(\tau)\right]$ and is static when demand is iid with known parameters. In this case, $O(\tau)=D(\tau)$, which is a pure pull system, and the order variance equals the demand variance: There is no bullwhip effect.

In reverse logistics supply chains, even when demand and return flow parameters are known, and demand is iid, the order-up-to level (4) may fluctuate since it is based on estimated lead time net demand. As a consequence, the variability of orders will differ from the variability of demands even when demands are iid and its parameters are known.

Table ?? compares the ratio of the standard deviation of orders to the standard deviation of demands $\left(\sigma_{O(\tau)} / \sigma_{N D(\tau)}\right)$ across methods $\mathrm{B}, \mathrm{C}$ and $\mathrm{D}$, and according to the replenishment lead time $L$, the demand standard deviation $\sigma_{D}$, the return probability $p$ and the expected time to return $(1 / q)$. As with forward supply chains, the magnification in (net) demand variability increases in the replenishment lead time and in the underlying demand variability. We observe that Method $\mathrm{C}$ consistently dominates Methods $\mathrm{B}$ and $\mathrm{D}$ in our simulations. This is because it makes better use of the periodlevel data than Method B by including return information, and it is more robust than Method D in its calculation of lead-time net demand because it uses aggregate information rather than item-level information. On the other hand, the relative performance of the methods changes depending on the underlying parameters: The largest differences in performance are seen at high return probabilities, at long return delays and at low demand variances.

\section{Managerial Implications.}

Our recommendation concerning minimizing the bullwhip effect in reverse logistics supply chains is to use Method $\mathrm{C}$ since it generates the lowest order variability. At the same time, Method B (that requires less information) can be used without generating a much larger order variability when the replenishment lead time is short, the demand variance is high, the return probability is low and/or the return delay is short. 


\begin{tabular}{|c|c|cc|cc|}
\hline \multirow{2}{*}{$\left(L, \sigma_{D}, p, q\right)$} & $\mathbf{C}$ & \multicolumn{2}{|c|}{$\mathbf{B}$} & \multicolumn{2}{|c|}{$\mathbf{D}$} \\
\cline { 2 - 6 } & $\sigma_{O(\tau)} / \sigma_{N D(\tau)}$ & $\sigma_{O(\tau)} / \sigma_{N D(\tau)}$ & rel. perf. & $\sigma_{O(\tau)} / \sigma_{N D(\tau)}$ & rel. perf. \\
\hline \hline$(\mathbf{2}, 6,0.5,0.6)$ & 1.89 & 1.99 & $5.63 \%$ & 2.08 & $10.56 \%$ \\
$(\mathbf{4}, 6,0.5,0.6)$ & 1.93 & 2.06 & $6.88 \%$ & 2.15 & $11.62 \%$ \\
$(\mathbf{8}, 6,0.5,0.6)$ & 1.94 & 2.08 & $7.11 \%$ & 2.16 & $11.62 \%$ \\
\hline$(4, \mathbf{4}, 0.5,0.6)$ & 1.66 & 1.81 & $8.99 \%$ & 1.92 & $15.62 \%$ \\
$(4, \mathbf{6}, 0.5,0.6)$ & 1.93 & 2.06 & $6.88 \%$ & 2.15 & $11.62 \%$ \\
$(4, \mathbf{8}, 0.5,0.6)$ & 2.09 & 2.21 & $6.00 \%$ & 2.29 & $9.87 \%$ \\
\hline$(4,6, \mathbf{0 . 5}, 0.6)$ & 1.93 & 2.06 & $6.88 \%$ & 2.15 & $11.62 \%$ \\
$(4,6, \mathbf{0 . 7}, 0.6)$ & 2.75 & 3.16 & $14.88 \%$ & 3.36 & $22.31 \%$ \\
$(4,6, \mathbf{0 . 9}, 0.6)$ & 5.00 & 6.47 & $29.33 \%$ & 6.92 & $38.24 \%$ \\
\hline$(4,6,0.5, \mathbf{0 . 4})$ & 1.84 & 1.95 & $6.35 \%$ & 2.21 & $20.40 \%$ \\
$(4,6,0.5, \mathbf{0 . 6})$ & 1.93 & 2.06 & $6.88 \%$ & 2.15 & $11.62 \%$ \\
$(4,6,0.5, \mathbf{0 . 8})$ & 2.05 & 2.15 & $5.25 \%$ & 2.05 & $0.35 \%$ \\
\hline
\end{tabular}

Table 4: Comparison of the ratio of the standard deviation of orders to the standard deviation of net demand $\left(\frac{\sigma_{O(\tau)}}{\sigma_{N D(\tau)}}\right)$ with respect to $L, \sigma_{D}, p$ and $q$ when parameters are known and as given in the first column $\left(\mu_{D}=30, h_{s}=\right.$ $\left.1, c_{b}=50\right)$. All other parameters are known and as in the base case. The relative performance is calculated with respect to the benchmark case $\mathrm{C}$, and shows how much higher the ratio $\frac{\sigma_{O(\tau)}}{\sigma_{N D(\tau)}}$ is with respect to that of the base case. 


\section{Conclusion}

In this article, we discussed the information needs of a number of strategic, tactical and operational decisions concerning return flow characteristics and touched on the concept of actively influencing returns. We then reviewed methods for forecasting future returns based on historical sales and returns in two blocks: developing a return delay model and estimating its parameters, and forecasting future returns. Finally, we turned to an operational level decision process: inventory control. The inventory management literature for remanufacturable products, for the most part, develops the inventory control tools without analyzing the combined performance of the tool and the forecasting methods that drive it. This article reports research that attempts to do this, and takes it one step further by considering supply-chain performance through an analysis of order variability in reverse logistics.

There are several trade-offs to be made in choosing the parameter estimation model and the forecasting method. Specifically, the data requirements of methods using period-level information are lower than those using itemlevel information. However, the parameter convergence rate of period-level forecast models is lower, leading to a longer time over the total life-cycle of the product where the parameter estimates are inaccurate. Similarly, comparing forecasting methods requiring differing levels of information (in particular, the four methods proposed by Kelle and Silver 1999a), we see that these methods differ in their cost performance under inaccurate parameter estimation and in the order variability that they generate. Noting that the estimation method chosen will dictate the extent and duration of the parameter inaccuracy, we conclude that convergence rate and robustness to parameter inaccuracy should be jointly considered.

We first summarize the results of the individual analysis. The singlestage cost performance of Method A that uses only an estimate of the return probability in forecasting and ordering is very poor and is not recommended for practical implementation. Again from a single-stage cost perspective, Methods B, C and D yield similar cost (with D dominating) under correct parameter information, despite the fact that Method $\mathrm{D}$ requires item-level information and Methods $\mathrm{B}$ and $\mathrm{C}$ require only period-level information. On the other hand, when parameters are unknown and estimated inaccurately, Method D is not the best method. In particular, Method B is more robust

under inaccurate estimation of the return probability, with Methods $\mathrm{C}$ and $\mathrm{D}$ having similar performance. Methods $\mathrm{B}$ and $\mathrm{C}$ are much more robust un- 
der the inaccurate estimation of the expected time to return than Method D. Finally, Methods C, B and D give rise to increasing levels of order variability, in that order. We also find that for low sales volumes, item-level information clearly dominates period-level information from a parameter convergence perspective, whereas for higher sales volumes, period-level information may be sufficiently accurate.

To conclude, we synthesize these findings in the light of the trade-offs discussed above. In particular, jointly considering these trade-offs leads us to conclude that different methods may be appropriate at different time points and different product volumes. While parameter error is high, it may be worth using Method B due to its superior single-stage cost performance despite the fact that it generates a higher order variance. After parameter estimates converge, switching to Method $\mathrm{C}$ is recommended since its cost performance is good and it generates the lowest order variability. For lowdemand products, if period-level information is used, parameter estimation error could persist for a longer portion of the life-cycle of the product. Therefore, for such products, we recommend investing in collecting item-level information for parameter estimation, at least initially, and using Methods B and $\mathrm{C}$, in that order, for forecasting. For high-demand products, such an investment is not recommended, instead, collecting and using only period-level information for both parameter estimation and forecasting is recommended.

\section{Research Directions.}

The poor behavior of the simplest method, Method A, is mainly due to the fact that the reported optimal safety factor $k^{*}$ is inappropriate because the net demand during lead time is poorly estimated. Adjusting this value would considerably improve Method A's performance. Another option is to use Method A, but assuming that demands and returns are fully uncorrelated instead of fully correlated. This has the advantage that net demand is overestimated rather than underestimated, reducing costly stockouts. Recall that the impact of inaccurate information about the return distribution seems to be rather limited. Based on this observation, one could construct a method whose performance lies between Method A and B by using Method B with a pre-specified return distribution (for instance the uniform distribution) rather than an estimated one. This considerably reduces the information need, while we expect to maintain a reasonable performance.

An important assumption with respect to the results on the impact of inaccurate estimation is that the system parameters do not change over time. 
It would be interesting to study the impact of inaccurate estimation in a dynamic environment where the underlying parameters to be estimated change over time, in which parameter forecasts are continuously updated, but not necessarily converging due to changing parameters.

Most contributions in this field have focused on applications in inventory control. Other fields that address operational-level decisions, such as production planning, warehousing, etc. may be affected in a similar way and call for further research on the value of information.

Finally, as discussed in Section 2, there is little research on identifying factors that significantly influence return flow characteristics. Developing a good understanding of drivers of return flow characteristics would enable better decision making for influencing return flows.

\section{Acknowledgements}

We thank Atalay Atasu for coding the simulations generating Table 4.

\section{References}

[1] Box, G. E. P. and G. M. Jenkins. 1976. Time Series Analysis, Forecasting and Control, revised edition, Holden-Day, San Francisco.

[2] Cox, D. R. and D. Oakes. 1984. Analysis of Survival Data. Chapman and Hall, London.

[3] De Brito, M.P. and M.B.M. de Koster. 2003. "Handling Product Returns: warehousing issues" in R. Dekker, K. Inderfurth, L.N. van Wassenhove, M. Fleischmann (eds.), Quantitative Approaches for Reverse Logistics. Springer-Verlag, forthcoming.

[4] De Brito, M. P. and R. Dekker. 2003. Modelling Product Returns in Inventory Control - Exploring the Validity of General Assumptions. International Journal of Production Economics, 81-82 225-241.

[5] De Brito, M. P. and E.A. van der Laan. 2002. Inventory management with product returns: the impact of (mis)information, Econometric Institute Report EI 2002-29, Erasmus University Rotterdam, the Netherlands. 
[6] Debo, L., C. Savaşkan and L.N. Van Wassenhove. 2003. "Coordination in Closed-Loop Supply Chains " in R. Dekker, K. Inderfurth, L.N. van Wassenhove, M. Fleischmann Quantitative Approaches for Reverse Logistics. Springer-Verlag, forthcoming.

[7] Dempster, A. P., N. M. Laird and D. B. Rubin. 1977. Maximum Likelihood from Incomplete Data via the EM Algorithm (with Discussion). J. Royal Stat. Soc. Series B. 339 1-22.

[8] Dhrymes, P. J. 1985. Distributed Lags. North-Holland, Amsterdam.

[9] Dowling, M. 1999. Getting Less in Return. Catalog Age. 16 (4), pp. 1,18.

[10] Fleischmann, M., J. Bloemhof-Ruwaard, P. Beullens and R. Dekker. 2003. "Reverse Logistics Netowrk Design" in R. Dekker, K. Inderfurth, L.N. van Wassenhove and M. Fleischmann (eds.), Quantitative Approaches for Reverse Logistics. Springer-Verlag, forthcoming.

[11] Gallup International Institute. 1992. The Health of the Planet Survey. Gallup International Institute, Princeton, NJ.

[12] Goh, T. N. and N. Varaprasad. 1986. A Statistical Methodology for the Analysis of the Life-Cycle of Reusable Containers. IIE Transactions. 18 (1) $42-47$.

[13] Goldstein, L. 1994. The Strategic Management of Environmental Issues: A Case Study of Kodak's Single-use Cameras. M.S. Thesis, Sloan School of Management, MIT, Cambridge, MA.

[14] Gooley, T. G. 2001. Diminishing Returns. Logistics Management and Distribution Report. 40 (6), p. 43.

[15] Guide, D. and L.N. Van Wassenhove. 2002. Managing Product Returns at HP. INSEAD Case.

[16] Hess, J. D. and G. E. Mayhew. 1997. Modeling Merchandise Returns in Direct Marketing. Journal of Direct Marketing. 11 (2) 20 - 35.

[17] Inderfurth, K., S.D.P. Flapper, F. Lambert, C. Pappis and Voutsinas. 2003. "Production Planning for Product Recovery Management" in R. Dekker, K. Inderfurth, L.N. van Wassenhove and M. Fleischmann Quantitative Approaches for Reverse Logistics. Springer-Verlag, forthcoming. 
[18] Kelle, P. and E. A. Silver. 1989a. Forecasting the Returns of Reusable Containers. Journal of Operations Management. 8 17-35.

[19] Kelle, P. and E. A. Silver. 1989b. Purchasing Policy of New Containers Considering the Random Returns of Previously Issued Containers. IIE Transactions. 21 349-354.

[20] Kiesmüller, G., Kleber and S. Minner. 2003. "Managing Dynamic Product Recovery: An Optimal Control Perspective" in R. Dekker, K. Inderfurth, L.N. van Wassenhove and M. Fleischmann (eds.), Quantitative Approaches for Reverse Logistics. Springer-Verlag, forthcoming.

[21] Kiesmuller, G. and E. van der Laan. 2001. An inventory model with dependent product demands and returns. International Journal of Production Economics. 72 (1) 73-87.

[22] Kokkinaki, A., R. Zuidwijk, J.A.E.E. van Nunen and R. Dekker. 2003. "Information Management for Reverse Logistics" in R. Dekker, K. Inderfurth, L.N. van Wassenhove and M. Fleischmann (eds.), Quantitative Approaches for Reverse Logistics. Springer-Verlag, forthcoming.

[23] Klausner, M., W. M. Grimm and C. Hendrickson. 1998. Reuse of Electric Motors in Consumer Products. Journal of Industrial Ecology. 2(2) 89102.

[24] Lee, H. L., V. Padmanabhan and S. Whang. 1987. Information Distortion in a Supply Chain: The Bullwhip Effect. Management Science. 43(4) 546-558.

[25] Marx-Gómez, J., C. Rautenstrauch, A. Nurnberger and R. Kruse. 2002. Neuro-Fuzzy Approach to Forecast Returns of Scrapped Products to Recycling and Remanufacturing. Knowledge-Based Systems. 15 119-129.

[26] Moorty, S. and K. Srinivasan. 1995. Signaling Quality with Money-Back Guarantee: The Role of Transaction Costs. Marketing Science. 14 (4) $230-247$.

[27] Morrell, A. L. 2001. The Forgotten Child of the Supply Chain. Modern Materials Handling. 56 (6), $33-36$.

[28] OECD Environmental Data: Compendium 1999. 
[29] Pinkerton, J. 1997. Getting Religion about Returns. Dealerscope Consumer Electronics Marketplace. 39 (11) p. 19.

[30] Richardson, H. 2001. Logistics in Reverse. Industryweek. 250 (6), 37 40.

[31] Rosen, C. 2001. Ready for the Returns? Informationweek. January 8, $22-23$.

[32] Savaşkan, R. C., S. Bhattacharya and L. N. Van Wassenhove. 1999. Channel Choice and Coordination in a Remanufacturing Environment. INSEAD Working Paper 99(14/TM).

[33] Silver E.A., R. Peterson and D.F. Pyke. 1998. Inventory managementand production planning and schedulling, 3rd edition, John Wiley \& Sons, New York.

[34] Thierry, M., M. Salomon, J. van Nunen and L. N. Van Wassenhove. 1995. Strategic Issues in Product Recovery Management. California Management Review 37 (2) 114-135.

[35] Toktay, L. B. 2002. Forecasting Product Returns, in Business Perspectives in Closed-Loop Supply Chains, D. Guide, Jr., C. Corbett, R. Dekker, L.N Van Wassenhove, Eds. Carnegie Bosch Institute.

[36] Toktay, L. B., L. M. Wein and S. A. Zenios. 2000. Inventory Management of Remanufacturable Products. Management Science. 46 (11) 1412 1426 .

[37] Van der Laan, E.A., D. Vlachos, G. Kiesmueller, R. Kuik and R. Dekker. 2003. "Managing Recoverable Inventories" in R. Dekker, K. Inderfurth, L.N. van Wassenhove, M. Fleischmann (eds.), Quantitative Approaches for Reverse Logistics. Springer-Verlag, forthcoming.

[38] Zellner, A. 1987. An Introduction to Bayesian Inference in Econometrics. Robert E. Krieger Publishing Company, Malabar, Florida. 


\section{Publications in the Report Series Research* in Management}

ERIM Research Program: "Business Processes, Logistics and Information Systems"

\section{3}

Project Selection Directed By Intellectual Capital Scorecards

Hennie Daniels and Bram de Jonge

ERS-2003-001-LIS

Combining expert knowledge and databases for risk management

Hennie Daniels and Han van Dissel

ERS-2003-002-LIS

Recursive Approximation of the High Dimensional max Function

Ş. II. Birbil, S.-C. Fang, J.B.G. Frenk and S. Zhang

ERS-2003-003-LIS

Auctioning Bulk Mobile Messages

S.Meij, L-F.Pau, E.van Heck

ERS-2003-006-LIS

Induction of Ordinal Decision Trees: An MCDA Approach

Jan C. Bioch, Viara Popova

ERS-2003-008-LIS

A New Dantzig-Wolfe Reformulation And Branch-And-Price Algorithm For The Capacitated Lot Sizing Problem With Set Up Times

Zeger Degraeve, Raf Jans

ERS-2003-010-LIS

Reverse Logistics - a review of case studies

Marisa P. de Brito, Rommert Dekker, Simme D.P. Flapper

ERS-2003-012-LIS

Product Return Handling: decision-making and quantitative support

Marisa P. de Brito, M. (René) B. M. de Koster

ERS-2003-013-LIS

Managing Product Returns: The Role of Forecasting

Beril Toktay, Erwin A. van der Laan, Marisa P. de Brito

ERS-2003-023-LIS

Improved Lower Bounds For The Capacitated Lot Sizing Problem With Set Up Times

Zeger Degraeve, Raf Jans

ERS-2003-026-LIS

In Chains? Automotive Suppliers and Their Product Development Activities

Fredrik von Corswant, Finn Wynstra, Martin Wetzels

ERS-2003-027-LIS

* A complete overview of the ERIM Report Series Research in Management: http://www.erim.eur.nl

ERIM Research Programs:

LIS Business Processes, Logistics and Information Systems

ORG Organizing for Performance

MKT Marketing

F\&A Finance and Accounting

STR Strategy and Entrepreneurship 
Mathematical models for planning support

Leo G. Kroon, Rob A. Zuidwijk

ERS-2003-032-LIS

How and why communications industry suppliers get "squeezed out" now, and the next phase

L-F Pau

ERS-2003-033-LIS

Financial Markets Analysis by Probabilistic Fuzzy Modelling Jan van den Berg, Uzay Kaymak, Willem-Max van den Bergh ERS-2003-036-LIS

WLAN Hot Spot services for the automotive and oil industries :a business analysis or : "Refuel the car with petrol and information, both ways at the gas station "

L-F Pau, M.H.P.Oremus

ERS-2003-039-LIS 